\title{
A temática evasão escolar no contexto do PROEJA: uma revisão integrativa
}

\section{The thematic dropout in the context of PROEJA: a review integrative.}

\author{
Paula Lucas de Oliveira ${ }^{1}$; Nilva Celestina Do Carmo ${ }^{2}$
}

\begin{abstract}
RESUMO: O presente trabalho trata-se de uma revisão integrativa a partir da contextualização do Programa Nacional de Integração da Educação Profissional com a Educação Básica, na Modalidade de Jovens e Adultos - PROEJA e as temáticas: evasão/abandono escolar. Foram considerados artigos e trabalhos acadêmicos, dissertações e teses. Disponíveis em duas bases de dados, no período entre 2009 e 2019 . Ressaltando aqueles que foram produzidos entre 2009 e 2012 por serem datas que marcaram o término da primeira e segunda remessa de cursos disponibilizados desde a sua criação (2006). Visando compreender sobre as questões que proporcionaram a Evasão/abandono escolar, esse trabalho também, disponibiliza outras evidências, trazidas pela metodologia Análise de Conteúdo, aplicada aos artigos e trabalhos acadêmicos que se destacaram na revisão integrativa, dos quais emergiram duas categorias: trabalho/remuneração/benefícios e Professores. A primeira categoria destaca a necessidade da manutenção da sobrevivência, através do trabalho, mesmo que informal. A segunda categoria denota a falta de preparo do corpo docente frente à modalidade de ensino para jovens e adultos. Sendo assim, conclui-se que essa política pública não atendeu, na sua totalidade, aos objetivos previstos.
\end{abstract}

PALAVRAS-CHAVE: PROEJA, evasão/abandono escolar.

ABSTRACT: The present work is an integrative review based on the contextualization of the National Program for the Integration of Professional Education with Basic Education, in the Youth and Adult Modality - PROEJA and the themes: school dropout / dropout. Academic articles and papers, dissertations and theses were considered. Available in two databases, in the period between 2009 and 2019.Highlighting those that were produced between 2009 and 2012 for being dates that marked the end of the first and second shipment of courses available since its creation (2006). In order to understand the issues that caused dropout / dropout, this work also provides other evidence, brought by the Content Analysis methodology, applied to academic articles and papers that stood out in the integrative review, from which two categories emerged: work / remuneration / benefits and Teachers. The first category highlights the need to maintain survival through work, even if informal. The second category denotes the lack of preparation of the teaching staff in face of the teaching modality for young people and adults. Therefore, it is concluded that this public policy did not fully meet the objectives set.

KEYWORDS: PROEJA, evasion/ school dropout.

\footnotetext{
1 Discente do curso de Pós-graduação em Docência na Educação Profissional e Tecnológica do Instituto Federal de Educação, Ciência e Tecnologia do Sudeste de Minas Gerais - campus Rio Pomba. Professora de Ciências da rede municipal de educação do município de São Geraldo - MG. E-mail: paulaoliveirabio@ hotmail.com

2 Mestre em Economia Doméstica. Professora do Instituto Federal de Educação Ciência e Tecnologia do Sudeste de Minas Gerais. E-mail: nilva.carmo@ifsudestemg.edu.br ORCID: https://orcid.org/0000-0002-7520-2382
} 


\section{INTRODUÇÃO}

De acordo com o Ministério da Educação (MEC) O Proeja foi criado inicialmente pelo Decreto $n^{\circ}$. 5.478, de 24/06/2005 e denominado como Programa de Integração da Educação Profissional ao Ensino Médio na Modalidade Educação de Jovens e Adultos. Sua criação foi uma decisão governamental de atender à demanda de jovens e adultos pela oferta de educação profissional técnica de nível médio, da qual em geral são excluídos, bem como, em muitas situações, do próprio ensino médio(BRASIL, 2006).

Frigotto et al (2005) destaca que os setores expressivos da sociedade compreenderam a necessidade de se implementar uma política pública de formação profissional, integrada ao sistema público de emprego e a educação básica, tendo em vista que o MEC se ocupava da educação profissional técnica, sem se atentar para as demandas sociais dos trabalhadores jovens e adultos que realizavam cursos supletivos de nível fundamental e o Ministério do Trabalho e Emprego desenvolvia seu plano de formação sem se preocupar com a recuperação da escolaridade e a organização de itinerários formativos. O perfil esperado para este aluno é que ele seja capaz de qualificar-se para o trabalho contribuindo para aumentar os índices de pessoas com uma escolaridade mais elevada e consequentemente amenizar a taxa de analfabetismo (ALMEIDA, 2008).

Assim, nos termos do documento base do Programa Nacional de Integração da Educação Profissional com a Educação Básica na Modalidade de Educação de Jovens e Adultos (PROEJA), que apresenta as orientações acerca da implantação do programa, o trabalho é entendido como princípio educativo; o direito ao trabalho como um valor estruturante da cidadania; a qualificação como uma política de inclusão social e um suporte indispensável do desenvolvimento sustentável (BRASIL, 2009).

Em 2006, esse programa foi substituído pelo "Programa Nacional de Integração da Educação Profissional com a Educação Básica na Modalidade de Educação de Jovens e Adultos” (Decreto n. 5.840, de 13/07/2006), mantendo-se a sigla PROEJA. E, além das instituições da Rede Federal de Educação Profissional e Tecnológica foram habilitadas as instituições públicas de ensino estaduais e municipais, as entidades privadas nacionais de serviço social, aprendizagem e formação profissional vinculadas ao Sistema S (SENAI, SESI, SENAR...) para a oferta de cursos e programas de educação profissional, agora, articulados a educação básica de forma integrada e concomitante (BRASIL, 2006).

O Documento Base do PROEJA (BRASIL, 2007) ressalta a necessidade da implantação de um programa como esse na Rede Federal de Educação para que ela retome o papel social que lhe cabe: 
Denotada na Rede Federal a ausência de sujeitos alunos com o perfil típico dos encontrados na EJA, cabe - mesmo que tardiamente - repensar as ofertas até então existentes e promover a inclusão desses sujeitos, rompendo com o ciclo das apartações educacionais, na educação profissional e tecnológica. Nesse contexto, o Governo Federal, por meio do Ministério da Educação, convida a Rede Federal de Educação Profissional e Tecnológica para atuar como referência na oferta do ensino médio integrado à educação profissional na modalidade EJA (BRASIL, 2007. p. 34).

Essa mudança foi promovida visando atender algumas das reivindicações de setores da educação, tais como: os profissionais da educação da Rede Federal de Ensino, os estudiosos do assunto e os gestores educacionais. Uma das reivindicações se baseava em ampliar a abrangência dos vínculos entre a EJA e a educação profissional, que diz respeito à oferta de cursos, bem como os locais onde seriam oferecidos (MOREIRA, 2012).

Outra alteração promovida, diz respeito à carga horária dos cursos. Na primeira versão, os cursos destinados à formação inicial e continuada de trabalhadores, possuíam mil e quatrocentas (1.400) horas, como carga horária mínima e os cursos de educação profissional técnica de nível médio possuíam a carga horária de duas mil e quatrocentas (2.400) horas. Na nova versão de implantação do PROEJA, para a estruturação do curso, deve-se observar as diretrizes existentes no Decreto 5.840/2006, o qual afirma em seu artigo $5^{\circ}$, parágrafo único:

Art. $5^{\circ}$ As instituições de ensino ofertantes de cursos e programas do PROEJA serão responsáveis pela estruturação dos cursos oferecidos e pela expedição de certificados e diplomas. Parágrafo único. As áreas profissionais escolhidas para a estruturação dos cursos serão, preferencialmente, as que maior sintonia guardarem com as demandas de nível local e regional, de forma a contribuir com o fortalecimento das estratégias de desenvolvimento socioeconômico e cultural (BRASIL, 2006).

Pedrosa (2016) enfatiza que as políticas públicas educacionais devem atender a uma demanda de jovens e adultos de modo a impulsionar os processos de inovação tecnológica, favorecer o aumento de produtividade da economia, bem como propiciar melhores condições de inserção ocupacional e de remuneração do trabalho.

Portanto, a educação é um catalizador do desenvolvimento econômico, como enfatizado por Caleiro (2010). O autor ainda cita o reconhecimento generalizado da importância da educação. Os benefícios dessa seriam individuais como: saúde, produtividade e sociais como a redução dos efeitos da pobreza.

No entanto, no Brasil, o PROEJA tem como um dos seus desafios integrar três campos de educação que, historicamente, não estão próximos, quais sejam: a formação profissional técnica de nível médio, o ensino médio e a educação de jovens e adultos (MARQUES e NETO, 2019). Nesse mesmo diapasão, Baracho, Henrique e Moura (2013), salientam que o PROEJA tem outro desafio, 
que é o de formar e qualificar jovens e adultos trabalhadores para os diversos setores da economia, em conformidade com as demandas do desenvolvimento local, além de garantir-lhes uma efetiva incorporação à sociedade.

Nesse contexto, tem-se que observar que ações educativas de jovens e adultos e os seus desafios não são recentes. De acordo com Haddad e Di Pierro (2000) já acontecia desde o período colonial e possuem um histórico marcado por insucessos, apesar do número significativo de iniciativas governamentais. Os autores destacam ações como: o Movimento Brasileiro de Alfabetização MOBRAL em 1967, o Ensino Supletivo criado em 1971 pela Lei de Diretrizes e Bases da Educação Nacional (nº 5.692/71), a Fundação Educar, na década de 80 vinculada ao Ministério da Educação, que ofertava apoio técnico e financeiro às iniciativas de alfabetização existentes (VIEIRA, 2004 apud MIRANDA et.al, 2016), o Brasil Alfabetizado e o PROJOVEM em 2003.

Para Miranda, Souza e Pereira (2016) o que se viu, até então, foi à criação de programas, em curto prazo, que não garantem que os alunos deem continuidade aos estudos. A EJA no Brasil é marcada pela descontinuidade e por tênues políticas públicas, insuficientes para dar conta da demanda potencial e do cumprimento do direito, nos termos estabelecidos pela Constituição Federal de 1988 (MIRANDA, SOUZA E PEREIRA, 2016).

Apesar da reestruturação e da importância do PROEJA como política pública educacional, este enfrentou outro grande desafio, que diz respeito à permanência dos estudantes nos cursos. Moreira (2012, p.13), destaca:

\begin{abstract}
Não obstante os aspectos positivos do PROEJA, ele enfrenta um sério problema no que diz respeito à permanência dos estudantes na escola. A quantidade de indivíduos que evade dos cursos é muito elevada. A elevada evasão escolar no PROEJA demonstra a necessidade de se estudar os fatores que contribuem para esse fenômeno, como aqueles referentes à escola, à família ou mesmo ao próprio indivíduo. A evasão escolar é um processo que tem seu início e o seu processo, muitas vezes possíveis de serem identificados, monitorados e, quando possível, evitados.
\end{abstract}

De acordo com as informações contidas na Plataforma Nilo Peçanha (PNP), implementada pela Secretaria de Educação Profissional e Tecnológica do Ministério da Educação, destinada a coleta, tratamento e publicização de dados oficiais da Rede Federal de Educação Profissional, Científica e Tecnológica, no ano de 2017 do total de 9.526 matrículas realizadas em cursos integrados e concomitantes, $23,8 \%$ (4.295) dos alunos abandonaram os cursos, no ano de 2018 foram 10.149 matrículas e 21,27\% (3.869) de evadidos, 2019 foi o ano com menor número de matriculados - 9.412 e $19,71 \%$ (3.499) desses evadiram.(Plataforma Nilo Peçanha, 2017).

Dessa forma, o presente estudo tem como objetivo identificar os fatores que contribuíram para a evasão escolar dos alunos nos cursos técnicos do PROEJA e consequentemente na desconti- 
nuidade devido à redução dos cursos ofertados pelo Programa ao longo dos anos desde a sua implantação pelo decreto $\mathrm{n}^{\circ} 5.478 / 2005$ revogado posteriormente pelo decreto $\mathrm{n}^{\circ} 5.840 / 2006$, através de uma revisão bibliográfica sistemática, com abordagem integrativa a partir da contextualização do PROEJA e evasão/abandono escolar.

\section{DESENVOLVIMENTO}

\section{METODOLOGIA}

Esse trabalho trata-se de uma revisão integrativa, um método que proporciona a síntese de conhecimento e a incorporação da aplicabilidade de resultados de estudos significativos na prática sendo muito utilizada, originalmente, na área da saúde, possibilitando identificar as melhores evidências e sintetizá-las, para fundamentar propostas de mudanças (SOUZA et al, 2009). Portanto, entende-se que a sua aplicação seja muito relevante também para a área da educação, através de evidências trazidas por outros autores, a fim de propor melhorias e aspectos relevantes para essa metodologia de ensino denominada PROEJA.

Foram considerados artigos e trabalhos acadêmicos, dissertações e teses, do período de 2009 a 2019 por meio de dados disponíveis em duas bases de dados: Biblioteca Digital Brasileira de Teses e Dissertações (http://bdtd.ibict.br/vufind/) e Google Acadêmico (https://scholar.google.com.br/), utilizando os descritores combinados e também individualmente: PROEJA e evasão/abandono escolar.

A escolha do período 2009 a 2019 se justifica pela presença de estudos sobre a evasão escolar nos cursos do PROEJA serem mais evidentes a partir do ano de 2009, ano esse que seria o de conclusão das primeiras turmas desses cursos que foram iniciados em 2006. O ano de 2020 não entrou nessas pesquisas devido ao período atípico que estamos vivendo com a pandemia do COVID-19 (Coronavírus), vírus que, segundo a Organização Mundial de Saúde (OMS) começou a ser disseminado em dezembro de 2019, na cidade de Wuhan, na China e vem se espalhando exponencialmente por todo o globo terrestre e causando milhões de mortes.

Os critérios para a seleção e inclusão dos estudos, foram definidos após a leitura dos resumos das publicações. Desta forma, foram consideradas publicações com palavras chaves no título e palavras chaves em todos os campos, estudos científicos publicados entre 2009 e 2019 e referências bibliográficas de maior visibilidade e impacto (Quadro 01). 


\section{Quadro 1: Critérios de inclusão de estudos científicos sobre o tema "PROEJA", no período de 2009 a 2019.}

\begin{tabular}{|c|c|c|c|c|}
\hline Item & Critérios & Descrição & Justificativa & Pontuação \\
\hline 1 & $\begin{array}{l}\text { Palavras chave no } \\
\text { título e palavras chave } \\
\text { em todos os campos. }\end{array}$ & $\begin{array}{l}\text { Estudos científicos que } \\
\text { apresentem pelo menos } \\
\text { uma das palavras chave da } \\
\text { pesquisa }\end{array}$ & $\begin{array}{l}\text { Foram selecionados } \\
\text { estudos científicos que } \\
\text { apresentem no título e ou } \\
\text { em todos os campos pelo } \\
\text { menos uma das palavras } \\
\text { chave da pesquisa. }\end{array}$ & $\begin{array}{c}\text { Todas as Palavras chave no } \\
\text { título }=3 \\
\text { Pelo menos } 1 \text { das Palavras } \\
\text { chave no Título e as demais } \\
\text { nos demais campos }=2 \\
\text { Todas as palavras chave } \\
\text { apenas nos demais } \\
\text { campos }=1 \\
\text { Máximo de } 3 \text { pontos. }\end{array}$ \\
\hline 2 & Ano de publicação & $\begin{array}{l}\text { Estudos científicos } \\
\text { publicados a partir do ano } \\
\text { de } 2009 \text {. }\end{array}$ & $\begin{array}{l}\text { Considerou-se o período de } \\
\text { dez anos, com base na data } \\
\text { de implementação do } \\
\text { PROEJA, em âmbito } \\
\text { nacional, ter ocorrido a } \\
\text { partir de 2006, valorizando } \\
\text { as publicações próximas a } \\
\text { esta data. }\end{array}$ & $\begin{array}{c}2009 \text { até } 2012=3 \text { pontos; } \\
2013 \text { até } 2015=2 \text { pontos; } \\
>2016=1 \text { ponto } \\
\text { Máximo de } 3 \text { pontos }\end{array}$ \\
\hline 3 & Tipos de Publicação & $\begin{array}{l}\text { Teses, Dissertações, Artigo } \\
\text { em Revista - Qualis Capes, } \\
\text { Monografias, Artigo em } \\
\text { Revista sem Qualis Capes } \\
\text { ou Trabalho completo } \\
\text { apresentado em evento e } \\
\text { Artigo publicado em site. }\end{array}$ & $\begin{array}{l}\text { Referências bibliográficas } \\
\text { de maior visibilidade e } \\
\text { impacto científico }\end{array}$ & $\begin{array}{c}\text { Tese }=6 \\
\text { Dissertação }=5 \\
\text { Artigo em Revista }- \text { Qualis } \\
\text { Capes }=4 \\
\text { Monografia }=3 \\
\text { Artigo em Revista Sem } \\
\text { Qualis Capes ou } \\
\text { Trabalho completo } \\
\text { apresentado em evento }=2 \\
\text { Artigo completo publicado } \\
\text { em site }=1 \\
\text { Máximo de } 6 \text { pontos }\end{array}$ \\
\hline
\end{tabular}

Fonte: Dados da pesquisa (2020).

As publicações realizadas entre 2009 e 2012 foram melhores pontuadas devido à relevância dos fatos analisados, considerando maior probabilidade de utilização de dados primários, assim como as publicações mais recentes (>2016) obtiveram menores pontuações devido a probabilidade desses estudos serem baseados, em sua maioria, em dados secundários de anos anteriores. Para esse estudo as teses e dissertações foram de maior relevância, desta maneira obtiveram maiores pontuações.

Após a identificação das referências, foi realizada uma leitura dos resumos das publicações, sendo utilizados os seguintes critérios de exclusão: estudos científicos publicados antes de 2009, os 
não pertinentes aos assuntos e os repetidos. Foram destacados aqueles estudos que despertaram o interesse, sendo realizada a leitura dos documentos na íntegra e preenchida uma ficha bibliográfica previamente elaborada com os seguintes tópicos: autor, título, tipo de publicação, local da publicação, ano e resumo.

\section{RESULTADOS E DISCUSSÃO}

Com a finalidade de identificar publicações que destacamos casos de evasões e suas causas, especificamente no PROEJA, foi realizada uma busca nos sites da Biblioteca Digital Brasileira de Teses e Dissertações (25) e Google acadêmico (3.740) e obteve como resultado total de 3.765 publicações, pelos descritores "PROEJA" e "evasão" de formas individualizadas e foram encontradas, de acordo com o descritor PROEJA na Biblioteca Digital Brasileira de Teses e Dissertações 346 e 11.200 publicações no Google Acadêmico, de acordo com o descritor "evasão" foi encontrado 1.512 na Biblioteca Digital Brasileira de Teses e Dissertações e 189.000 no Google Acadêmico.

Foram selecionadas publicações relacionadas aos temas objetos desta pesquisa, com temas relacionados ao PROEJA e a evasão no programa. Conforme descrito na Tabela 01, evidenciou-se que o Google Acadêmico constituiu o principal meio de divulgação dos trabalhos relacionados às temáticas.

Tabela 1: Número de estudos científicos encontrados de acordo com as palavras-chave, no período de 2009 a 2019.

\begin{tabular}{lcc}
\hline \multicolumn{1}{c}{ Descritores } & $\begin{array}{c}\text { Biblioteca Digital } \\
\text { Brasileira }\end{array}$ & Google Acadêmico \\
\hline PROEJA e evasão/ abandono escolar & 6 & 14 \\
PROEJA & 6 & 4 \\
Evasão/ abandono & 2 & 3 \\
Total & $\mathbf{1 4}$ & $\mathbf{2 1}$ \\
\hline
\end{tabular}

Fonte: Dados da pesquisa (2020)

Considerando os critérios estabelecidos na metodologia e a pontuação adquirida, foram selecionados 14 das 35 publicações, considerando que a análise se pautou naquelas publicações que seriam mais relevantes ao assunto e as que obtiveram maiores pontuações. A partir do somatório das pontuações propostas obteve-se um total de 14 estudos possíveis, conforme pontuação obtida pelas publicações selecionadas, de acordo com a Tabela 02. 


\section{Tabela 2: Pontuação final das publicações científicas selecionadas a partir dos critérios da revisão integrativa, no período de 2009 a 2019.}

\section{PROEJA E EVASÃO}

\begin{tabular}{|c|c|c|c|c|}
\hline Título do estudo & $\begin{array}{c}\text { Palavra } \\
\text { chave }\end{array}$ & $\begin{array}{c}\text { Ano da } \\
\text { publicação }\end{array}$ & $\begin{array}{c}\text { Tipo de } \\
\text { publicação }\end{array}$ & Total \\
\hline $\begin{array}{l}\text { 1. Um estudo do e no processo de implantação no estado } \\
\text { do Paraná do PROEJA: problematizando as causas da } \\
\text { evasão. }\end{array}$ & 3 & 3 & 5 & 11 \\
\hline $\begin{array}{l}\text { 2. Evasão escolar no curso do programa nacional de } \\
\text { Integração da Educação profissional com a educação } \\
\text { básica na modalidade de EJA (PROEJA). }\end{array}$ & 3 & 3 & 5 & 11 \\
\hline $\begin{array}{l}\text { 3. Evasão escolar nos cursos técnicos do PROEJA na rede } \\
\text { federal de educação profissional e tecnológica de Minas } \\
\text { Gerais. }\end{array}$ & 3 & 3 & 5 & 11 \\
\hline $\begin{array}{l}\text { 4. A problemática da evasão de estudantes vinculados ao } \\
\text { PROEJA no IF Baiano- Campus Guanambi. }\end{array}$ & 3 & 3 & 5 & 11 \\
\hline $\begin{array}{l}\text { 5. Evasão no PROEJA: Estudo das causas no Instituto } \\
\text { Federal de Educação, Ciência e Tecnologia do } \\
\text { Maranhão/IFMA - Campus Monte Castelo. }\end{array}$ & 3 & 3 & 5 & 11 \\
\hline $\begin{array}{l}\text { 6. A evasão no PROEJA ministrado pelo Instituto Federal } \\
\text { do Espírito Santo campus Santa Tereza. }\end{array}$ & 3 & 3 & 5 & 11 \\
\hline $\begin{array}{l}\text { 7.O programa nacional de integração da educação } \\
\text { profissional com a educação básica na modalidade de } \\
\text { educação de jovens e adultos (PROEJA) em um centro } \\
\text { estadual de educação profissional: evasão e remanescência. }\end{array}$ & 3 & 2 & 5 & 10 \\
\hline
\end{tabular}

\section{PROEJA}

\begin{tabular}{l|c|c|c}
\hline $\begin{array}{l}\text { 8. A implementação do PROEJA na rede federal de } \\
\text { educação profissional e tecnológica: visão dos gestores. }\end{array}$ & 3 & 3 & 5 \\
\hline $\begin{array}{l}\text { 9. Gestão de processos pedagógicos no PROEJA: razão de } \\
\text { acesso e permanência. }\end{array}$ & 3 & 3 & 5 \\
\hline $\begin{array}{l}\text { 10. PROEJA: mais do que uma possibilidade de } \\
\text { qualificação profissional? }\end{array}$ & 3 & 3 & 5 \\
\hline $\begin{array}{l}\text { 11. O ensino do PROEJA como estratégia de cidadania e } \\
\text { inclusão profissional. }\end{array}$ & 3 & 2 & 11 \\
\hline $\begin{array}{l}\text { 12. O PROEJA no Instituto Federal de Goiás - Campus } \\
\text { Goiânia: Um estudo sobre fatores de acesso e permanência } \\
\text { na escola. }\end{array}$ & 3 & 3 & 11 \\
\hline
\end{tabular}




\section{Tabela 2: Pontuação final das publicações científicas selecionadas a partir dos critérios da revisão integrativa, no período de 2009 a 2019. - Continuação}

\section{EVASÃO}

\begin{tabular}{l|c|c|c}
\hline $\begin{array}{l}\text { 13. Evasão escolar no curso técnico agrícola na modalidade } \\
\text { de Educação de Jovens e Adultos da Escola Agrícola }\end{array}$ & 3 & 3 & 5 \\
Federal de Rio do Sul- SC. & & 3 & 11 \\
\hline $\begin{array}{l}\text { 14. Educação de Jovens e Adultos e a evasão escolar: o } \\
\text { caso do Instituto Federal do Ceará - Campus de Fortaleza. }\end{array}$ & & 3 & 5 \\
\hline
\end{tabular}

Fonte: Dados da pesquisa (2020)

De acordo com os levantamentos realizados, verificou-se que 50\% das publicações referemse aos descritores "PROEJA e evasão", aproximadamente 35\% refere-se ao descritor "PROEJA" e somente $15 \%$, em média, referem-se ao descritor "evasão".

Verifica-se também que a maioria das publicações foi realizada na área de educação e somente uma publicação foi na área da psicologia, assim como a maioria das publicações (13) são dissertações de mestrado e somente uma refere-se a uma tese de doutorado. Além disso, procurouse verificar em quais áreas do conhecimento as publicações foram realizadas. Para tanto, buscou-se relacionar as informações sobre o tipo de periódico ou programa de pós-graduação, conforme apresentado no Quadro 02.

Quadro 2: Descrição das publicações de acordo com as áreas de conhecimento das publicações relativas ao período 2009 a 2019.

\begin{tabular}{|c|c|c|c|c|}
\hline \multicolumn{5}{|c|}{ PROEJA E EVASÃO/ABANDONO ESCOLAR } \\
\hline Item & Título da publicação & $\begin{array}{c}\text { Informações do } \\
\text { periódico/Programa de } \\
\text { Pós-Graduação }\end{array}$ & $\begin{array}{c}\text { Área de } \\
\text { Conhecimento }\end{array}$ & Metodologia \\
\hline 01 & $\begin{array}{l}\text { Um estudo do e no } \\
\text { processo de implantação } \\
\text { no estado do Paraná do } \\
\text { PROEJA: } \\
\text { problematizando as } \\
\text { causas da evasão. }\end{array}$ & $\begin{array}{l}\text { Pós-Graduação em } \\
\text { Educação. }\end{array}$ & $\begin{array}{c}\text { Educação, Cultura e } \\
\text { Tecnologia. }\end{array}$ & $\begin{array}{l}\text { Pesquisa qualitativa, através de } \\
\text { análise documental, entrevista com } \\
\text { Coordenadores de Curso, questionário } \\
\text { orquestrado com os alunos evadidos e } \\
\text { observação sistemática nas oficinas, } \\
\text { nos encontros e seminários e visita às } \\
\text { escolas que ofertam o PROEJA. }\end{array}$ \\
\hline 02 & $\begin{array}{l}\text { Evasão escolar no curso } \\
\text { do programa nacional de } \\
\text { Integração da Educação } \\
\text { profissional com a } \\
\text { educação básica na } \\
\text { modalidade de EJA } \\
\text { (PROEJA). }\end{array}$ & $\begin{array}{c}\text { Programa de Pós- } \\
\text { Graduação em Educação } \\
\text { Agrícola. }\end{array}$ & Educação Agrícola. & $\begin{array}{l}\text { Estudo de caso utilizando dados que } \\
\text { foram coletados através de um } \\
\text { questionário, com perguntas abertas e } \\
\text { fechadas, aplicados aos professores } \\
\text { do PROEJA do CEFET-Bambuí e aos } \\
\text { alunos evadidos desse curso, no } \\
\text { período de } 2006 \text { a } 2009 \text {. }\end{array}$ \\
\hline
\end{tabular}




\section{Quadro 2: Descrição das publicações de acordo com as áreas de conhecimento das publica- ções relativas ao período 2009 a 2019 - Continuação.}

\begin{tabular}{|c|c|c|c|c|}
\hline 03 & $\begin{array}{l}\text { Evasão escolar nos } \\
\text { cursos técnicos do } \\
\text { PROEJA na rede federal } \\
\text { de educação profissional } \\
\text { e tecnológica de Minas } \\
\text { Gerais. }\end{array}$ & $\begin{array}{c}\text { Programa de Pós- } \\
\text { Graduação em Educação }\end{array}$ & $\begin{array}{l}\text { Educação, Trabalho e } \\
\text { Formação Humana. }\end{array}$ & $\begin{array}{l}\text { Revisão bibliográfica, análise } \\
\text { informações referentes aos índices de } \\
\text { matrícula/evasão do PROEJA em } \\
\text { Minas Gerais e aplicação de } \\
\text { questionários autoaplicáveis para } \\
\text { alunos evadidos. }\end{array}$ \\
\hline 04 & $\begin{array}{l}\text { A problemática da } \\
\text { evasão de estudantes } \\
\text { vinculados ao PROEJA } \\
\text { no IF Baiano- Campus } \\
\text { Guanambi. }\end{array}$ & $\begin{array}{c}\text { Programa de Pós- } \\
\text { Graduação em Educação } \\
\text { Agrícola }\end{array}$ & Educação agrícola & $\begin{array}{l}\text { Estudo de caso utilizando pesquisa } \\
\text { documental, } \\
\text { semiestruturados aos docentionários } \\
\text { primeiro semestre de } 2011 \text { e aos } \\
\text { discentes das turmas de } 2009,2010 \text { e } \\
2011 \text { e ainda entrevista com os } \\
\text { evadidos. }\end{array}$ \\
\hline 05 & \begin{tabular}{lrr} 
Evasão no & \multicolumn{2}{c}{ PROEJA: } \\
Estudo das causas no & no \\
Instituto Federal & de \\
Educação, Ciência & e \\
Tecnologia & do \\
Maranhão/IFMA & - \\
Campus Monte Castelo.
\end{tabular} & $\begin{array}{c}\text { Programa de Pós- } \\
\text { Graduação em Educação }\end{array}$ & Educação & $\begin{array}{l}\text { Pesquisa quali-quantitativa com coletas } \\
\text { de dados realizados através de } \\
\text { entrevistas semiestruturadas com } \\
\text { alunos desistentes e alguns professores } \\
\text { do curso. }\end{array}$ \\
\hline 06 & $\begin{array}{l}\text { A evasão no PROEJA } \\
\text { ministrado pelo Instituto } \\
\text { Federal do Espírito Santo } \\
\text { campus Santa Tereza. }\end{array}$ & $\begin{array}{c}\text { Programa de Pós- } \\
\text { Graduação em Educação } \\
\text { Agrícola. }\end{array}$ & Educação & $\begin{array}{l}\text { Pesquisa documental em fontes } \\
\text { primárias do IFES-ST, questionários e } \\
\text { entrevistas com alunos matriculados, } \\
\text { ex-alunos, professores e evadidos. }\end{array}$ \\
\hline 07 & $\begin{array}{l}\text { O programa nacional de } \\
\text { integração da educação } \\
\text { profissional com a } \\
\text { educação básica na } \\
\text { modalidade de educação } \\
\text { de jovens e adultos } \\
\text { (PROEJA) em um centro } \\
\text { estadual de educação } \\
\text { profissional: evasão e } \\
\text { remanescência. }\end{array}$ & $\begin{array}{c}\text { Programa de Pós } \\
\text { Graduação em } \\
\text { Tecnologia, } \\
\text { Universidade } \\
\text { Tecnológica Federal do } \\
\text { Paraná }\end{array}$ & $\begin{array}{c}\text { Tecnologia e } \\
\text { Trabalho. }\end{array}$ & $\begin{array}{l}\text { Pesquisa quali-quantitativa, método } \\
\text { dialético- pesquisas documental, } \\
\text { bibliográfica e empírica - questionários } \\
\text { e entrevistas. }\end{array}$ \\
\hline
\end{tabular}

PROEJA

\begin{tabular}{|c|l|c|c|c|}
\hline 08 & $\begin{array}{l}\text { A implementação do } \\
\text { PROEJA na rede federal } \\
\text { educação profissional e } \\
\text { tecnológica: visão dos } \\
\text { gestores. }\end{array}$ & $\begin{array}{c}\text { Programa de pós- } \\
\text { graduação em Educação. }\end{array}$ & $\begin{array}{l}\text { Políticas Públicas e } \\
\text { Gestão da Educação }\end{array}$ & $\begin{array}{l}\text { Análise documental e entrevistas } \\
\text { semiestruturadas. }\end{array}$ \\
\hline 09 & $\begin{array}{l}\text { Gestão de processos } \\
\text { pedagógicos no } \\
\text { PROEJA: razão de } \\
\text { acesso e permanência. }\end{array}$ & $\begin{array}{c}\text { Programa de pós- } \\
\text { graduação em Educação. }\end{array}$ & $\begin{array}{c}\text { Políticas e gestão de } \\
\text { processos } \\
\text { educacionais. }\end{array}$ & $\begin{array}{l}\text { Realização de cunho qualitativo através } \\
\text { da realização de Grupo Focal e de } \\
\text { reunião com os professores do curso } \\
\text { Técnico em Administração. }\end{array}$ \\
\hline
\end{tabular}




\section{Quadro 2: Descrição das publicações de acordo com as áreas de conhecimento das publica- ções relativas ao período 2009 a 2019 - Continuação.}

\begin{tabular}{|c|l|c|c|c|}
\hline 10 & $\begin{array}{l}\text { PROEJA: mais do que } \\
\text { uma possibilidade de } \\
\text { qualificação } \\
\text { profissional? }\end{array}$ & $\begin{array}{l}\text { Programa de pós } \\
\text { graduação em Educação. }\end{array}$ & Educação & Revisão bibliográfica \\
\hline 11 & $\begin{array}{l}\text { O ensino do PROEJA } \\
\text { como estratégia de } \\
\text { cidadania e inclusão } \\
\text { profissional. }\end{array}$ & $\begin{array}{l}\text { Programa de pós- } \\
\text { graduação em Psicologia } \\
\text { Social }\end{array}$ & $\begin{array}{l}\text { Psicologia } \\
\text { nanátodo experimental e } \\
\text { quantitativo de questionário com } \\
\text { questões fechadas e escalas Likert de } \\
\text { cinco condições. }\end{array}$ \\
\hline 12 & $\begin{array}{l}\text { O PROEJA no Instituto } \\
\text { Federal de Goiás - } \\
\text { Campus Goiânia: Um } \\
\text { estudo sobre fatores de } \\
\text { acesso e permanência na } \\
\text { escola. }\end{array}$ & $\begin{array}{l}\text { Programa de pós- } \\
\text { graduação em Educação. }\end{array}$ & $\begin{array}{l}\text { Políticas Públicas e } \\
\text { Gestão da Educação } \\
\text { Profissional e } \\
\text { Tecnológica. }\end{array}$ & $\begin{array}{l}\text { Aplicação de questionários junto aos } \\
\text { discentes e gestores e entrevistas com } \\
\text { discentes e professores. }\end{array}$ \\
\end{tabular}

\begin{tabular}{|c|c|c|c|c|}
\hline \multicolumn{5}{|c|}{ EVASÃO } \\
\hline 13 & $\begin{array}{l}\text { Evasão escolar no curso } \\
\text { técnico agrícola na } \\
\text { modalidade de Educação } \\
\text { de Jovens e Adultos da } \\
\text { Escola Agrícola Federal } \\
\text { de Rio do Sul- SC. }\end{array}$ & $\begin{array}{c}\text { Programa de Pós- } \\
\text { Graduação em Educação } \\
\text { Agrícola. }\end{array}$ & $\begin{array}{l}\text { Educação e } \\
\text { Sociedade. }\end{array}$ & $\begin{array}{l}\text { Análise da literatura sobre políticas de } \\
\text { educação profissional e educação de } \\
\text { jovens e adultos, bem como, pesquisas } \\
\text { sobre evasão escolar, ainda foi } \\
\text { realizada a análise de documentos } \\
\text { oficiais, projeto pedagógico do curso, } \\
\text { registros escolares, relatórios e atas de } \\
\text { reuniões da EAFRS. Questionários aos } \\
\text { alunos matriculados no curso que } \\
\text { evadiram e outro aos que } \\
\text { permaneceram. }\end{array}$ \\
\hline 14 & $\begin{array}{l}\text { Educação de Jovens e } \\
\text { Adultos e a evasão } \\
\text { escolar: o caso do } \\
\text { Instituto Federal do Ceará } \\
\text { - Campus de Fortaleza. }\end{array}$ & $\begin{array}{c}\text { Programa de Pós- } \\
\text { graduação em educação } \\
\text { brasileira. }\end{array}$ & Educação & $\begin{array}{l}\text { Pesquisa bibliográfica, documental e de } \\
\text { campo, subsidiadas pelas técnicas de } \\
\text { grupo focal, de observação participante } \\
\text { e de entrevistas semiestruturadas, junto } \\
\text { aos segmentos investigados. }\end{array}$ \\
\hline
\end{tabular}


De acordo com a metodologia utilizada verifica- se que $92 \%$ das publicações basearam-se em uma pesquisa qualitativa, esse tipo de pesquisa utiliza-se de questionários e/ou entrevistas com docentes e discentes para desenvolver uma compreensão inicial, ou seja, para compreender a causa das evasões nos cursos do PROEJA, e, de acordo com Chaer et al (2011), tem o objetivo de alcançar uma compreensão qualitativa das razões e motivações subjacentes. Malhotra (2006, p. 108) conceitua pesquisa qualitativa como uma "metodologia de pesquisa não estruturada e exploratória, baseada em pequenas amostras que proporcionam percepções e compreensão do contexto do problema”.

Somente uma publicação, de Lampert (2010) utilizou da revisão bibliográfica como metodologia de trabalho. O seu referencial teórico foi desenvolvido a partir dos estudos de Frigotto (2002), Kuenzer (1999) e Arroyo (1996) para discutir questões relacionadas à escola e o mundo do trabalho e do estudo de Fonseca (2016) para problematizar questões relacionadas ao trabalho infanto-juvenil.

Através da análise de conteúdos, conforme metodologia proposta por Bardin (2011) e Laville e Dionne (1999) buscou-se evidenciar as categorias que emergiram da análise dos conteúdos dos itens pesquisados. Através da busca integrada entre os descritores "PROEJA e evasão", foram encontrados os principais motivos que levaram os estudantes a abandonar os cursos e, na sequência foram separados por categorias, resultando em: 1) Trabalho/remuneração/ benefícios; 2) Horários; 3) Falta de conhecimentos necessários/ escolaridade; 4) Professores (despreparo, ausências, cobranças excessivas); 5) Transporte/distância; 6) Questões familiares- particularidades. A descrição da síntese das principais considerações pode ser visualizada no Quadro 3.

\section{Quadro 03 - Apresentação das categorias emergidas da análise de conteúdo sobre as sinopses e principais considerações referentes às temáticas: PROEJA e evasão/abandono escolar nas publicações selecionadas das bases Biblioteca Digital Brasileira de Teses e Dissertações e Google Acadêmico no período de 2009 a 2019.}

\begin{tabular}{|c|c|c|c|}
\hline Título das publicações & Sinopses & Principais considerações & Categorias \\
\hline $\begin{array}{l}\text { Um estudo do e no processo de } \\
\text { implantação no estado do } \\
\text { Paraná do } \\
\text { problematizando as causas da } \\
\text { evasão. }\end{array}$ & $\begin{array}{l}\text { A autora } \text { analisa } \text { aspectos da } \\
\text { eficiência política e social e } \\
\text { também a problematização de } \\
\text { possíveis condições para a } \\
\text { efetividade social do PROEJA, } \\
\text { por meio } \text { do } \\
\text { socioeconômico e as razões da } \\
\text { evasão no ano de } 2008 \text { no Estado } \\
\text { do Paraná. }\end{array}$ & $\begin{array}{l}32 \% \text { dos entrevistados deixaram de } \\
\text { frequentar o curso devido à } \\
\text { compatibilidade com o horário de } \\
\text { trabalho. A maioria não conseguia } \\
\text { chegar para a primeira aula } \\
\text { comprometendo a grade curricular } \\
\text { que prevê frequência de } 75 \% \text { nas } \\
\text { aulas. Em último lugar, a } \\
\text { aprendizagem ficou comprometida } \\
\text { com a ausência de professores } \\
\text { licenciados em sala de aula. }\end{array}$ & $\begin{array}{c}\text { Horários } \\
\text { Transporte/ } \\
\text { distância } \\
\text { Professores } \\
\text { (despreparo, } \\
\text { ausências, } \\
\text { cobranças } \\
\text { excessivas) }\end{array}$ \\
\hline
\end{tabular}




\section{Quadro 03 - Apresentação das categorias emergidas da análise de conteúdo sobre as sinopses e principais considerações referentes às temáticas: PROEJA e evasão/abandono escolar nas publicações selecionadas das bases Biblioteca Digital Brasileira de Teses e Dissertações e Google Acadêmico no período de 2009 a 2019 - Continuação.}

\begin{tabular}{|c|c|c|c|}
\hline $\begin{array}{l}\text { Evasão escolar no curso do } \\
\text { programa nacional } \\
\text { Integração de da } \quad \text { Educação } \\
\text { profissional com a educação } \\
\text { básica na modalidade de EJA } \\
\text { (PROEJA). }\end{array}$ & $\begin{array}{l}\text { Identificar e analisar as } \\
\text { possíveis lacunas }\end{array}$ & $\begin{array}{l}\text { A falta de oferta de bolsas de estudos } \\
\text { foi a principal causa de dificuldade } \\
\text { citada pelos discentes entrevistados. } \\
\text { Em relação às dificuldades com } \\
\text { procedimentos de avaliação durante a } \\
\text { realização do curso técnico } 32,3 \% \\
\text { consideraram que esse fator } \\
\text { influenciou a decisão de abandono. } \\
\text { Em relação aos docentes dos cursos, } \\
\text { a maioria (93\%) afirma não terem } \\
\text { participado de nenhum programa de } \\
\text { capacitação sobre o PROEJA. }\end{array}$ & $\begin{array}{c}\text { Trabalho/ } \\
\text { remuneração/ } \\
\text { Benefícios } \\
\text { Falta de } \\
\text { conhecimentos } \\
\text { necessários/ } \\
\text { escolaridade. } \\
\text { Professores } \\
\text { (despreparo, } \\
\text { ausências, } \\
\text { cobranças } \\
\text { excessivas) }\end{array}$ \\
\hline $\begin{array}{l}\text { Evasão escolar nos cursos } \\
\text { técnicos do PROEJA na rede } \\
\text { federal de educação profissional } \\
\text { e tecnológica de Minas Gerais. }\end{array}$ & $\begin{array}{l}\text { Identificar fatores que } \\
\text { influenciam a evasão escolar } \\
\text { nos cursos técnicos do PROEJA } \\
\text { na Rede Federal de Educação } \\
\text { Profissional e Tecnológica de } \\
\text { Minas Gerais (RFEPT-MG). }\end{array}$ & $\begin{array}{l}\text { Os maiores índices apresentados } \\
\text { foram os fatores necessidade de } \\
\text { trabalhar e dificuldade de conciliar o } \\
\text { horário de estudo e trabalho para a } \\
\text { decisão de abandonar o curso, } 64,4 \% \\
\text { e } 66 \% \% \text {, respectivamente. }\end{array}$ & $\begin{array}{c}\text { Trabalho/ } \\
\text { Remuneração/ } \\
\text { Benefícios } \\
\text { Horários }\end{array}$ \\
\hline $\begin{array}{l}\text { A problemática da evasão de } \\
\text { estudantes vinculados ao } \\
\text { PROEJA no IFBaiano- Campus } \\
\text { Guanambi. }\end{array}$ & $\begin{array}{l}\text { Caracterizada como estudo de } \\
\text { caso, teve como desígnio } \\
\text { analisar a problemática da } \\
\text { evasão no PROEJA no Instituto } \\
\text { Federal Baiano - Campus } \\
\text { Guanambi. }\end{array}$ & $\begin{array}{l}\text { Uma das dificuldades mais } \\
\text { destacadas foi o problema com os } \\
\text { transportes. Além disso, o programa } \\
\text { foi considerado insuficiente pelo } \\
\text { autor, pelo fato de não ter sido } \\
\text { atrativo as demandas dos estudantes } \\
\text { por ter sido implantado em } \\
\text { atendimento ao interesse do próprio } \\
\text { campus e não as demandas de } \\
\text { emprego da região, levando os alunos } \\
\text { a evadirem em busca de trabalhos } \\
\text { informais. }\end{array}$ & $\begin{array}{l}\text { Trabalho/ } \\
\text { Remuneração/ } \\
\text { Benefícios } \\
\text { Transporte/ } \\
\text { distância }\end{array}$ \\
\hline $\begin{array}{l}\text { Evasão no PROEJA: Estudo } \\
\text { das causas no Instituto Federal } \\
\text { de Educação, Ciência e } \\
\text { Tecnologia do Maranhão/IFMA } \\
\text { - Campus Monte Castelo. }\end{array}$ & $\begin{array}{l}\text { Investigar as causas da evasão } \\
\text { na percepção dos alunos } \\
\text { desistentes e de professores do } \\
\text { Programa, no curso técnico } \\
\text { integrado de Química de } \\
\text { Alimentos, no campus Monte } \\
\text { Castelo no IFET Maranhão no } \\
\text { período de } 2007 \text { a } 2010 .\end{array}$ & $\begin{array}{l}\text { Os alunos participantes eram em sua } \\
\text { maioria de uma classe com baixo } \\
\text { poder aquisitivo com renda média de } \\
\text { um salário mínimo e buscavam } \\
\text { melhorar suas condições em relação à } \\
\text { profissão, porém houve diversas } \\
\text { fragilidades na estruturação do } \\
\text { PROEJA, a começar pela mudança da } \\
\text { grade curricular do curso de dois para } \\
\text { três anos o que levou os alunos } \\
\text { optarem pelo trabalho ao estudo. A } \\
\text { pesquisa apontou que } 60 \% \text { dos } \\
\text { entrevistados afirmaram trabalhar e } \\
100 \% \text { responderam que o trabalho } \\
\text { interferia nos seu desempenho. }\end{array}$ & $\begin{array}{c}\text { Trabalho/ } \\
\text { Remuneração/ } \\
\text { Benefícios }\end{array}$ \\
\hline
\end{tabular}




\section{Quadro 03 - Apresentação das categorias emergidas da análise de conteúdo sobre as sinopses e principais considerações referentes às temáticas: PROEJA e evasão/abandono escolar nas publicações selecionadas das bases Biblioteca Digital Brasileira de Teses e Dissertações e Google Acadêmico no período de 2009 a 2019 - Continuação.}

\begin{tabular}{|c|c|c|c|}
\hline $\begin{array}{lcr}\text { A evasão } & \text { no } & \text { PROEJA } \\
\text { ministrado } & \text { pelo } & \text { Instituto } \\
\text { Federal do } & \text { Espírito Santo } \\
\text { campus Santa } & \text { Tereza. }\end{array}$ & $\begin{array}{l}\text { A autora faz um estudo da evasão } \\
\text { escolar no Curso PROEJA, } \\
\text { ministrado pelo Instituto Federal } \\
\text { do Espírito Santo Campus Santa } \\
\text { Teresa (IFESST). }\end{array}$ & $\begin{array}{l}\text { Os dados mostram-se coerentes em } \\
\text { virtude de o maior número de alunos, } \\
\text { serem do sexo masculino e enfrentar } \\
\text { carga diária de trabalho exacerbada e } \\
\text { com grande exigência física, o que } \\
\text { levava ao cansaço e ao não } \\
\text { aproveitamento e participação efetiva } \\
\text { em sala de aula. Os evadidos } \\
\text { também destacaram à necessidade de } \\
\text { colaborar com a renda da família, que } \\
\text { muitas vezes agrega outros que não } \\
\text { esposos (as) e filhos (as). }\end{array}$ & $\begin{array}{l}\text { Trabalho/ } \\
\text { Remuneração/ } \\
\text { Benefícios }\end{array}$ \\
\hline $\begin{array}{l}\text { O programa nacional de } \\
\text { integração da educação } \\
\text { profissional com a educação } \\
\text { básica na modalidade de } \\
\text { educação de jovens e adultos } \\
\text { (PROEJA) em um centro } \\
\text { estadual de } \\
\text { profissional: educação } \\
\text { remanescência. }\end{array}$ & $\begin{array}{l}\text { Esse trabalho analisa aspectos da } \\
\text { implementação, andamento e } \\
\text { atualidade do PROEJA (Programa } \\
\text { Nacional de Integração da } \\
\text { Educação Profissional com a } \\
\text { Educação Básica na Modalidade } \\
\text { de Educação de Jovens e } \\
\text { Adultos), em um Centro Estadual } \\
\text { de Educação Profissional. }\end{array}$ & $\begin{array}{l}\text { 90,9\% dos alunos tentavam conciliar } \\
\text { trabalho e estudo, com carga horária } \\
\text { de trabalho em torno de } 40 \text { horas } \\
\text { semanais. Ao serem questionados } \\
\text { alguns diziam que não iriam dar } \\
\text { conta de realizar o estágio ou que } \\
\text { chegavam atrasados devido ao } \\
\text { trabalho e a distância da instituição e } \\
\text { então optaram em abandonar o curso. }\end{array}$ & $\begin{array}{l}\text { Transporte/ } \\
\text { distância } \\
\text { Trabalho/ } \\
\text { Remuneração/ } \\
\text { Benefícios }\end{array}$ \\
\hline 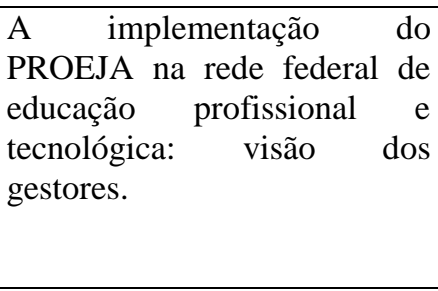 & $\begin{array}{l}\text { A autora faz uma análise da } \\
\text { gestão do Proeja na Rede Federal } \\
\text { a partir de sua implementação no } \\
\text { período de } 2005 \text { a } 2008 \text {. }\end{array}$ & $\begin{array}{l}\text { Em um dos campi analisados a } \\
\text { evasão se deu pela transferência de } \\
\text { alunos do setor de trabalho, um } \\
\text { número significante de empresas se } \\
\text { transferiram para o interior do estado } \\
\text { e os alunos optaram pela mudança } \\
\text { para garantir sua vaga de emprego. }\end{array}$ & $\begin{array}{l}\text { Trabalho/ } \\
\text { Remuneração/ } \\
\text { Benefícios }\end{array}$ \\
\hline $\begin{array}{lcr}\text { Gestão de } & \text { processos } \\
\text { pedagógicos no } & \text { PROEJA: } \\
\text { razão de } & \text { acesso } \\
\text { permanência } & & \end{array}$ & $\begin{array}{lrr}\text { Problematizar } & \text { a } & \text { gestão } \\
\text { pedagógica } & \text { vinculada } & \text { aos } \\
\text { processos de acesso, permanência } \\
\text { e sucesso escolar de estudantes no } \\
\text { PROEJA. }\end{array}$ & $\begin{array}{l}\text { Foram verificados dificuldades de } \\
\text { aprendizagem, especialmente no } \\
\text { componente matemática, tal situação } \\
\text { ocorre porque os professores } \\
\text { consideram consolidados os } \\
\text { conhecimentos do ensino } \\
\text { fundamental. Observam-se também } \\
\text { dificuldades em informática aplicada, } \\
\text { disciplina presente em quase todos os } \\
\text { cursos técnicos. Os relatos dos } \\
\text { estudantes expõem ainda a } \\
\text { necessidade da formação inicial e } \\
\text { continuada dos professores que atuam } \\
\text { na educação profissional, } \\
\text { principalmente em programas que } \\
\text { contemplam estudantes oriundos dos } \\
\text { meios populares, como o PROEJA. }\end{array}$ & $\begin{array}{c}\text { Falta de } \\
\text { conhecimentos } \\
\text { necessários/ } \\
\text { escolaridade. } \\
\text { Professores } \\
\text { (despreparo, } \\
\text { ausências, } \\
\text { cobranças } \\
\text { excessivas) }\end{array}$ \\
\hline $\begin{array}{l}\text { PROEJA: mais do que uma } \\
\text { possibilidade de qualificação } \\
\text { profissional? }\end{array}$ & $\begin{array}{l}\text { Este trabalho tem como } \\
\text { intencionalidade problematizar o } \\
\text { PROEJA enquanto possibilidade } \\
\text { de qualificação profissional para } \\
\text { sujeitos com trajetórias } \\
\text { descontínuas de trabalho e } \\
\text { escolarização e que trabalharam } \\
\text { no período infantojuvenil. }\end{array}$ & $\begin{array}{l}\text { Conciliar o trabalho e a escola } \\
\text { caracterizou, para alguns estudantes } \\
\text { do PROEJA um desencontro com a } \\
\text { escolarização, mesmo afirmando ser } \\
\text { um sonho a conclusão dos estudos, } \\
\text { direito este que foi omitido a eles no } \\
\text { período infantojuvenil. }\end{array}$ & $\begin{array}{l}\text { Trabalho/ } \\
\text { Remuneração/ } \\
\text { Benefícios }\end{array}$ \\
\hline
\end{tabular}




\section{Quadro 03 - Apresentação das categorias emergidas da análise de conteúdo sobre as sinopses e principais considerações referentes às temáticas: PROEJA e evasão/abandono escolar nas publicações selecionadas das bases Biblioteca Digital Brasileira de Teses e Dissertações e Google Acadêmico no período de 2009 a 2019 - Continuação.}

\begin{tabular}{|c|c|c|c|}
\hline $\begin{array}{l}\text { O ensino do PROEJA como } \\
\text { estratégia de cidadania e } \\
\text { inclusão profissional. }\end{array}$ & $\begin{array}{l}\text { Analisar o ensino } \text { do } \\
\text { PROEJA/IFMT/Cuiabá como } \\
\text { estratégia de resgate da } \\
\text { cidadania e inclusão profissional } \\
\text { para os alunos. }\end{array}$ & $\begin{array}{l}\text { Quase a totalidade dos docentes } \\
\text { participantes da amostra pesquisada } \\
\text { respondeu haver muitas dificuldades } \\
\text { em fazer a construção dos } \\
\text { conhecimentos do ensino básico e } \\
\text { técnicos com os alunos do PROEJA, } \\
\text { já os discentes reclamavam pela } \\
\text { distância entre professor e aluno, por } \\
\text { falta de preparo dos mesmos. }\end{array}$ & $\begin{array}{l}\text { Professores } \\
\text { (despreparo, } \\
\text { ausências, } \\
\text { cobranças } \\
\text { excessivas) }\end{array}$ \\
\hline $\begin{array}{l}\text { O PROEJA no Instituto Federal } \\
\text { de Goiás - Campus Goiânia: } \\
\text { Um estudo sobre fatores de } \\
\text { acesso e permanência na escola. }\end{array}$ & $\begin{array}{l}\text { Este trabalho teve por finalidade } \\
\text { analisar os fatores de que } \\
\text { favorecem ou dificultam o } \\
\text { acesso e a permanência dos } \\
\text { estudantes do PROEJA } \\
\text { desenvolvido no campus } \\
\text { Goiânia do Instituto Federal de } \\
\text { Educação, Ciência e Tecnologia } \\
\text { de Goiás (IFG). }\end{array}$ & $\begin{array}{l}\text { Ao serem questionados sobre os } \\
\text { fatores que dificultam o acesso à } \\
\text { escola, a maioria dos estudantes } \\
\text { apontou a necessidade de priorizar o } \\
\text { trabalho, tendo em vista a } \\
\text { sobrevivência. }\end{array}$ & $\begin{array}{l}\text { Trabalho/ } \\
\text { remuneração/ } \\
\text { Benefícios }\end{array}$ \\
\hline $\begin{array}{l}\text { Evasão escolar no curso técnico } \\
\text { agrícola na modalidade de } \\
\text { Educação de Jovens e Adultos } \\
\text { da Escola Agrícola Federal de } \\
\text { Rio do Sul- SC. }\end{array}$ & $\begin{array}{l}\text { O trabalho busca compreender } \\
\text { as causas da evasão escolar } \\
\text { desses alunos. }\end{array}$ & $\begin{array}{l}\text { Destaca-se que 54\% dos alunos } \\
\text { evadidos o fizeram por razões } \\
\text { econômicas, pela necessidade de } \\
\text { trabalhar, o autor destaca ainda que } \\
\text { apesar de não ser apontada como } \\
\text { motivo, também pode ser causa de } \\
\text { evasão a percepção pelo aluno que a } \\
\text { vaga no mercado de trabalho não está } \\
\text { reservada para ele. Assim o aluno } \\
\text { ingressa na escola, com a perspectiva } \\
\text { de se capacitar para conquistar o } \\
\text { emprego, no entanto, a partir do } \\
\text { momento que consegue trabalho, } \\
\text { perde o interesse pelo estudo. O } \\
\text { emprego desta forma acaba } \\
\text { concorrendo com a escola e } \\
\text { induzindo o aluno, para a desistência. }\end{array}$ & $\begin{array}{c}\text { Trabalho/ } \\
\text { remuneração/ } \\
\text { Benefícios }\end{array}$ \\
\hline $\begin{array}{l}\text { Educação de Jovens e Adultos e } \\
\text { a evasão escolar: o caso do } \\
\text { Instituto Federal do Ceará - } \\
\text { Campus de Fortaleza. }\end{array}$ & $\begin{array}{l}\text { Identificar os fatores que } \\
\text { influenciaram, mais fortemente, } \\
\text { os alunos evadidos dos cursos } \\
\text { de nível médio integrados à } \\
\text { formação profissional na } \\
\text { modalidade EJA, no Instituto } \\
\text { Federal do Ceará (IFCE) - } \\
\text { campus de Fortaleza. }\end{array}$ & $\begin{array}{l}\text { O resultado das pesquisas evidencia } \\
\text { que a maioria dos professores do } \\
\text { IFCE, campus de Fortaleza, não } \\
\text { estava preparada e nem disposta a } \\
\text { assumir o desafio -imposto pela } \\
\text { Direção, ao implantar os cursos de } \\
\text { EJA do PROEJA, sem as condições } \\
\text { mínimas de infraestrutura material e } \\
\text { - pessoal formado. A postura } \\
\text { adotada na prática pedagógica de } \\
\text { alguns professores claramente reflete- } \\
\text { se nos índices de evasão. }\end{array}$ & $\begin{array}{l}\text { Professores } \\
\text { (despreparo, } \\
\text { ausências, } \\
\text { cobranças } \\
\text { excessivas) }\end{array}$ \\
\hline
\end{tabular}


A categoria que mais se destacou nos artigos selecionados, com $72 \%$, foi a denominada “Trabalho/remuneração/benefícios" e está relacionada com a desistência dos alunos às causas financeiras. De acordo com o que Lampert (2011), cita em sua pesquisa, conciliar o trabalho e a escola caracterizou, para alguns estudantes do PROEJA, um desencontro com a escolarização. Corroborando com a autora, Silva (2014), Pereira (2011), Marconatto (2009) e Rocha (2011) evidenciam a necessidade de trabalhar para garantir a sobrevivência como causa principal da evasão uma vez que, os horários das aulas estavam tendo incompatibilidade com os horários das atividades profissionais e muitos estudantes diziam não chegar a tempo ou não possuírem o tempo necessário para executar o estágio obrigatório.

Moreira (2012) destaca os fatores necessidade de trabalhar e dificuldade de conciliar o horário de estudo e trabalho para a decisão de abandonar o curso, $64,4 \%$ e $66 \%$, respectivamente e Bonfim (2012) acredita que os alunos evadiram dos cursos do PROEJA a procura de trabalhos informais uma vez que, de acordo com o autor os cursos oferecidos não atenderam a demanda dos estudantes e sim aos interesses da própria instituição.

A outra categoria em destaque, com $35 \%$, trata-se do corpo docente dos cursos e é intitulada "Professores (despreparo, ausências, cobranças excessivas)". Corroborando com o que evidencia a pesquisa, Almeida (2009) cita que é essencial que seja ofertado aos professores uma formação continuada ao longo do curso na forma presencial e a distância com professores orientadores, mas, embora tenha um item específico sobre formação continuada dos professores que atuarão no PROEJA isso não foi consolidado e Vieira (2009), destaca que $93 \%$ dos professores não participaram de nenhum programa de capacitação sobre o PROEJA.

Moura e Henrique (2012) afirmam que, em geral, a alta taxa de evasão tem origem no uso de material didático inadequado para a faixa etária, nos conteúdos sem significado, nas metodologias infantilizadas aplicadas por professores despreparados, muitas críticas foram tecidas sobre o PROEJA: principalmente sobre esse despreparo dos professores da rede federal para atender o público da Educação de Jovens e Adultos (MOURA, 2008).

\section{CONSIDERAÇÕES FINAIS}

Objetivou-se neste trabalho identificar alguns fatores que, possivelmente, tenham contribuído com a evasão dos alunos dos cursos oferecidos pelo PROEJA. Esses fatores foram categorizados, como: 1) Trabalho/remuneração/ benefícios; 2) Horários; 3) Falta de conhecimentos necessários/ escolaridade; 4) Professores (despreparo, ausências, cobranças excessivas); 5) Transporte/distância; 6) Questões familiares- particularidades. 
Dentre esses fatores, considerando a metodologia utilizada, destacam-se as categorias: 1) Trabalho/remuneração/ benefícios e 4) Professores (despreparo, ausências, cobranças excessivas).

Da análise da categoria "Professores (despreparo, ausências, cobranças excessivas)", verifica-se a insatisfação dos discentes relacionada com a ausência constante de professores nas salas de aula. Outro ponto relevante, destacado nos achados, está, especialmente, o despreparo e a falta de proximidade nas relações professor-aluno e ainda a utilização de metodologias infantilizadas. Ao mesmo tempo que se infere como fator negativo, nesta mesma categoria, de forma bem incipiente, percebe-se que a proposta pedagógica e a didática utilizada, em alguns casos é, em certa medida, exaltada e valorizada pelos alunos.

Desse modo, nota-se que o professor designado a ministrar aulas junto a salas de EJA/PROEJA necessita desenvolver mais habilidades que aquelas comumente exigidas em seu trabalho junto aos cursos regulares, em virtude das peculiaridades verificadas nesta modalidade de ensino, porém, apenas a sua vontade e empenho não são suficientes para que vençam as barreiras que se impõem; é preciso que lhe seja oferecida a formação necessária para que possa atender a esses alunos de maneira satisfatória.

Para isso, há de se reconhecer que se faz necessária à implementação de ações que estimulem a participação dos docentes em grupos de estudo sobre legislação do PROEJA e suas diversas modalidades, além de fomentar a participação em cursos de formação inicial e continuada e em programas que contemplem estudantes oriundos dos meios populares.

No que tange, a categoria trabalho/remuneração/benefícios, denota-se que para o público atendido pelo PROEJA o trabalho é uma necessidade vital. Considerando que muitos alunos possuem a obrigação de colaborar com a renda da família, que muitas vezes agrega outros entes familiares, que não esposos (as) e filhos (as), esses discentes buscam pela profissionalização e capacitação necessárias a fim de assumirem cargos e atividades que possam lhes proporcionar uma posição social diferente.

Tendo em vista, o Estado possuir um papel fundamental na provisão de políticas públicas que promovam a inclusão escolar, a inserção no mercado de trabalho, como tantas outras ações que tem como conseguinte o combate à pobreza e melhoria nas condições de vida, infere-se que as instituições, ao implantar cursos voltados para o público atendido pelo PROEJA, devem considerar o princípio da proporcionalidade, prescrito nas Diretrizes Curriculares Nacionais para a EJA e repensar nos tempos e espaços ressaltados pelo Documento Base da Educação Profissional Técnica de Nível Médio/Ensino Médio. Desta forma, constata-se que apenas ofertar os cursos, sem a construção das ações por todos os envolvidos no processo educativo, não foi suficiente para alcançar e favorecer o atendimento das especificidades dos jovens e adultos, públicos do programa. 
Ou seja, as ações institucionais para a implantação e a manutenção desses alunos, até a conclusão dos cursos, não deram conta de abarcar a proposta social e inclusiva que o programa se propunha.

O estudo ainda possibilitou verificar a necessidade de aprofundar as pesquisas a fim de compreender as demais categorias referentes às causas que levaram a índices elevados de evasões e contribuíram para que o número de instituições a ofertar os cursos do PROEJA fossem reduzidos exponencialmente.

Além de explorar essa seara, de compreensão das demais categorias, por fim, vislumbra-se também, com as novas pesquisas, a possibilidade de encontrar alternativas viáveis e motivadoras, que possivelmente induziriam ações, tais como: a conciliação do trabalho com o estudo. Os resultados que emergirem desses estudos poderão contribuir, de forma significativa, para orientar ações que, consequentemente, proporcionarão a diminuição dos índices da evasão escolar dos alunos nos cursos técnicos do PROEJA.

Isso, de certa forma, além de garantir a subsistência dos participantes, serviria para aprimorar a prática, favorecer a aprendizagem, gerar profissionais capacitados. Essas ações conjugadas, consequentemente, diminuiriam, de forma significativa, a evasão escolar dos alunos nos cursos técnicos do PROEJA.

Este trabalho para além das temáticas discutidas evidencia também a necessidade de aprofundar as discussões quanto à avaliação do impacto de outros conceitos relacionados à empregabilidade e a competência, conceitos esses também incutidos no cenário educacional capitalista que visam aumentar a lucratividade por meio de investimento em educação, especificamente técnica, sem necessariamente garantir um aumento da escolaridade da classe trabalhadora. Em épocas de retração da economia, as pessoas mais afetadas pelo desemprego são aquelas que possuem formação intermediária, por isso é imprescindível uma perspectiva emancipatória, aliada ao caráter dualista da educação, reforçado, sobretudo, pelo governo brasileiro, seja desvendado, permitindo que os trabalhadores atuem criticamente num processo de construção de uma política nacional de educação profissional que contemple seus interesses, e não somente os do Capital.

\section{REFERÊNCIAS}

ALMEIDA, A. Um estudo do e no processo de implantação no estado do Paraná do proeja: problematizando as causas da evasão. 2008. Dissertação apresentada ao Curso de Pós-Graduação em Educação da Universidade Federal do Paraná. Disponível em: https://www. acervodigital.ufpr.br/bitstream/handle/1884/18631/DISSERTACAO\%202009.pdf? sequence=1\&isA llowed=y Acesso em 16 abr. 2020. 
ALMEIDA, O. C. S. Evasão em cursos à distância: validação de instrumentos, fatores influenciadores e cronologia da desistência. 2007. Dissertação de mestrado do Curso de Gestão Social e Trabalho, Faculdade de Economia, Administração, Contabilidade e Ciência da Informação e Documentação. Universidade de Brasília - DF, 2008. Disponível em: https://repo sitorio.unb.br/bitstream/10482/3912/1/2007_OniliaCristinadeSouzadeAlmeida.PDF. Acesso em: 23 jul. 2020.

ARROYO, M. Educação básica de Jovens e Adultos, Escola Plural. Secretaria Municipal de Educação de Belo Horizonte, 1996. Disponível em: http://www.dominiopublico.gov.br/ download/texto/me002220.pdf Acesso em: 17 abr. 2020.

BARACHO, M. G.; SILVA, A. C. R. Formação de educadores para o PROEJA: intervir para integrar. CEFET-RN. Natal - RN, 2007. Disponível em: https://memoria.ifrn.edu.br/bitstream/ handle/1044/1476/Forma\%C3\%A7\%C3\%A3o\%20de\%20Educadores\%20para\%20o\%20PROEJA.p df? sequence=1 Acesso em: 20 abr. 2020.

BARDIN, L. Análise de Conteúdo. 5. ed. Lisboa: Edições 70, 2011.

BONFIM, S. V. M. S. A problemática da evasão de estudantes vinculados ao proeja no IF baiano - campus Guanambi. Dissertação (Programa de pós-graduação em educação agrícola) Universidade Federal Rural do Rio de Janeiro, [Seropédica-RJ]. Disponível em: https://tede.ufrrj.br/handle/jspui/1537. Acesso em: 20 abr. 2020.

BRASIL. Ministério da Educação- Secretaria de Educação Profissional e Tecnológica. Programa de integração da Educação Profissional ao ensino médio na modalidade de educação de jovens e adultos - PROEJA - documento base, 2009. Departamento de Políticas e Articulação Institucional. Coordenação-Geral de Políticas de Educação Profissional e Tecnológica. Disponível em: http://portal.mec.gov.br/arquivos/pdf/acs_proeja.pdf. Acesso em: 21 abr. 2020.

BRASIL. Programa Nacional de Integração da Educação Profissional com a Educação Básica na modalidade de educação de jovens e adultos. Educação profissional técnica de nível médio / ensino médio. Documento base, Brasília, agosto 2007. Disponível em: http://portal.mec.gov. br/setec/arquivos/pdf2/proeja_medio.pdf. Acesso em: 21 abr. 2020.

BRASIL, Ministério da Educação. Programa Nacional de Integração da Educação Profissional com a Educação Básica na Modalidade de Educação de Jovens e Adultos (Proeja) -2006. Disponível em: http://portal.mec.gov.br/proeja Acesso em: 22 abr. 2020.

BRASIL, Ministério da Educação. Plataforma Nilo Peçanha. Brasília, 2017. Disponível em: http:/ /plataformanilopecanha.mec.gov.br/. Acesso em: 05 abr. 2021.

CALEIRO, A. B. Educação e Desenvolvimento: Que tipo de relação existe? Conference: I Encontro Luso-Angolano em Economia, Sociologia e Desenvolvimento Rural. Universidade de Évora, Évora, Portugal, 2010. Disponível em: https://www.researchgate.net/publication/308419711_ Educacao_e_Desenvolvimento_Que_tipo_de_relacao_existe. Acesso em 02 mai. 2020.

CHAER, G.; DINIZ, R. R P. RIBEIRO, E. A. A técnica do questionário na pesquisa educacional. SEDUC- PR, 2011. Disponível em: http://www.educadores.diaadia.pr.gov.br/arquivos /File/maio2013/sociologia_artigos/pesqusia_social.pdf. Acesso em: 28 jul. 2020. 
FONSECA, L. S. Trabalho Infanto-Juvenil: concepções, contradições e práticas políticas. Universidade Federal Fluminense, UFF, Brasil, 2016. Tese de Doutorado. Disponível em: https:// lume.ufrgs.br/bitstream/handle/10183/77972/000589122.pdf? sequence=1\&isAllowed=y Acesso em: 24 jul. 2020.

FRIGOTTO, G.; CIAVATTA, M.; RAMOS, M. A política de educação profissional no Governo Lula: um percurso histórico controvertido. Educação \& Sociedade. Campinas, v. 26, n. 92, p. 1087-1113, out. 2005. Disponível em http://www.scielo.br/scielo.php?script=sci_arttext\&pid= S010173302005000300017\&lng=pt\&nrm=iso. Acesso em: 12 ago. 2020. http://dx.doi.org/10.1590 /S0101-73302005000300017.

FRIGOTTO, G. A dupla face do trabalho: criação e destruição da vida. In: A experiência do trabalho e a educação básica. Rio de Janeiro: DP\&A, 2002. Disponível em: https: //www.scielo.br/scielo.php?script=sci_nlinks\&ref=000188\&pid=S14132478201100020001000004 \&lng=em. Acesso em: 12 mai.2020.

HADDAD, S.; DI PIERRO, M. C. Escolarização de jovens e adultos. Revista Brasileira de Educação, São Paulo, n. 14, p. 108-130, maio-ago/2000.

LAMPERT, F. G. PROEJA: mais do que uma possibilidade de qualificação profissional? Dissertação de mestrado - Universidade do Vale do Rio dos Sinos - São Leopoldo - RS, 2011. Disponível em: http://www.repositorio.jesuita.org.br/handle/UNISINOS/4545. Acesso em: 20 abr. 2020.

LAVILLE, C.; DIONNE, J. Análise de conteúdo. A construção do saber: Manual de metodologia da pesquisa em Ciências Humanas, Porto Alegre: Artmed; Belo Horizonte: Editora UFMG. 1999.

MALHOTRA, N. Pesquisa de marketing: uma orientação aplicada. 4. Ed. Porto Alegre: Bookman, 2006. Disponível em: https://books.google.com.br/books?hl=pt-BR\&lr=\&id=2B-QDwAAQ BAJ\&oi=fnd\&pg=PR1\&dq=Pesquisa+de+marketing:+uma+orienta\%C3\%A7\%C3\%A3o+aplicada \&ots=i6TSyC1BOB\&sig=azus38b4jIGIBc3e6lyZldDossU\#v=onepage\&q=Pesquisa\%20de\%20mar keting\%3A\%20uma\%20orienta\%C3\%A7\%C3\%A3o\%20aplicada\&f=false. Acesso em: 28 jul. 2020.

MARCONATTO. Lauri João. Evasão escolar no curso técnico agrícola na modalidade de EJA da Escola Agrotécnica Federal de Rio do Sul-SC. Dissertação (mestrado) - Universidade Federal Rural do Rio de Janeiro, Programa de Pós-Graduação em Educação Agrícola. 2009. Disponível em: https://tede.ufrrj.br/jspui/handle/tede/151. Aceso em: 30 mai. 2020.

MOREIRA, Priscila Rezende. Evasão escolar nos cursos técnicos do PROEJA na Rede Federal de Educação Profissional e Tecnológica de Minas Gerais. Dissertação - (Mestrado) Universidade Federal de Minas Gerais, Faculdade de Educação. UFMG/FaE, 2012. Disponível em: https://repositorio.ufmg.br/handle/1843/BUOS-99MFAU. Acesso em: 29 jun. 2020.

MOURA, Dante Henrique. A formação de docentes para a educação profissional e tecnológica. In: Revista Brasileira da Educação Profissional e Tecnológica, Ministério da Educação, Secretaria de Educação Profissional e Tecnológica. v.1, n.1, junho de 2008. Brasília: MEC, SETEC, 2008.Disponível em: http://www2.ifrn.edu.br/ojs/index.php/RBEPT/article/view/2863. Acesso em $13 / 01 / 2021$. 
MOURA D. H. e HENRIQUE A. L S. Proeja: entre desafios e possibilidades. HOLOS, Ano 28, Vol 2. Disponível em: http://www2.ifrn.edu.br/ojs/index.php/holos/article/view/914. Acesso em: 13 jan. 2021.

PAVÃO, M. F. R. SILVA, R. A. Educação de jovens e adultos/proeja e a problemática da evasão escolar. VII CONNEPI - Congresso Norte Nordeste de Pesquisa e Inovação. Disponível em: http://propi.ifto.edu.br/ocs/index.php/connepi/vii/paper/viewFile/3943/2741. Acesso em 05 jul. 2020.

PEDROSA, F. G. Política de educação profissional e tecnológica: análise da modalidade pronatec Brasil maior na perspectiva de seus implementadores. Dissertação (mestrado) - Instituto de Pesquisa EconômicaAplicada, Programa de Pós-Graduação em Políticas Públicas e Desenvolvimento, área de concentração em Economia, 2016. Disponível em: https://www.ipea. gov.br/sites/images/mestrado/turma2/fernanda-gomes-pedrosa.pdf. Acesso em: 05 jul. 2020.

PEREIRA, J. V. O PROEJA no Instituto Federal de Goiás - Campus Goiânia: Um estudo sobre os fatores de acesso e permanência na escola. 2011. 154 f., il. Dissertação (Mestrado em Educação)-Universidade de Brasília, Brasília, 2011. Disponível em: https:// repositorio.unb.br/handle/10482/9311?mode=full. Acesso em: 24 jul. 2020.

ROCHA,W. M. Educação de jovens e adultos e a evasão escolar: o caso do Instituto Federal do Ceará - campus de Fortaleza. 2011. 155 F. Dissertação (Mestrado em Educação) - Universidade Federal do Ceará. Faculdade de Educação, Programa de Pós-Graduação em Educação Brasileira, Fortaleza-CE, 2011. Disponível em: http://www.repositorio.ufc.br/handle/riufc/3039. Acesso em: 28 jul. 2020.

SANTOS, A. J.; GROSSI, M. G. R. Conhecendo o PROEJA: análise do documento-base da educação profissional. [S.1.], v. 15, n. 3, jun. 2011. ISSN 2317-7756. Disponível em: https://seer.dppg.cefetmg.br/index.php/revista-et/article/view/281. Acesso em: 16 abr. 2020.

SILVA, C. A. C. O Programa Nacional de Integração da Educação Profissional com a Educação Básica na Modalidade de Educação de Jovens e Adultos (PROEJA) em um Centro Estadual de Educação Profissional: evasão e remanescência. 2014. 111 f. Dissertação (Mestrado em Tecnologia) - Universidade Tecnológica Federal do Paraná, Curitiba, 2014. Disponível em: http://repositorio.utfpr.edu.br/jspui/handle/1/846. Acesso em 05 set. 2020.

SILVA, V. C. A implementação do PROEJA na rede federal de educação profissional e tecnológica: visão dos gestores. 2010. 178 f. Dissertação (Mestrado em Educação)-Universidade de Brasília, Brasília, 2010. Disponível em: http://bdtd.ibict.br/vufind/Record/UNB_5d083516226 a1ebda7e314e21885de9f. Acesso em: 06 set. 2020.

SOUZA, M. T.; SILVA, M. D.; CARVALHO, R. Revisão Integrativa: o que é e como fazer? Einstein. v. 8, n. 1, p. 102-106, mar. 2010.. Disponível em: https://journal.einstein.br/pt-br/ article/revisao-integrativa-o-que-e-e-como-fazer/. Acesso em: 05 abr. 2121.

VIEIRA, E. F. C .Evasão escolar no curso do Programa Nacional de Integração da Educação Profissional com a Educação Básica na Modalidade de Educação de Jovens e Adultos (PROEJA). 2009. 75 f. Dissertação (Mestrado em Educação Agrícola) - Instituto de Agronomia, Universidade Federal Rural do Rio de Janeiro, Seropédica - RJ, 2009. Disponível em: https://tede.ufrrj.br/handle/tede/148. Acesso em: 21 abr. 2020. 